\title{
Screen Printing Process Design of Experiments for Fine Line Printing of Thick Film Ceramic Substrates
}

\author{
Jianbiao Pan, Gregory L. Tonkay, Alejandro Quintero \\ Lehigh University \\ Dept. of Industrial and Manufacturing Systems Engineering \\ 200 W. Packer Ave \\ Bethlehem, PA 18015, USA
}

\begin{abstract}
Screen printing has been the dominant method of thick film deposition because of its low cost. Many experiments in industry have been done and many models of the printing process have been developed since the 1960's. With a growing need for denser packaging and a drive for higher pin count, screen printing has been refined to yield high resolution prints. However, fine line printing is still considered by industry to be difficult. In order to yield high resolution prints with high first pass yields and manufacturing throughput, the printing process must be controlled stringently.

This paper focuses on investigating the effect of manufacturing process parameters on fine line printing through the use of statistical design of experiments (DOE). The process parameters include print speed, squeegee hardness, squeegee pressure, and snap-off distance. Response variables are space widths of $10 \mathrm{mil}, 8 \mathrm{mil}$, and 5 mil lines in both parallel and perpendicular directions relative to the squeegee travel direction. It is concluded that the squeegee hardness and print speed have statistically significant effects on print quality. The harder the squeegee hardness and the lower the print speed within the range of values tested, the better the printed results. It was observed that the space width between perpendicular lines is narrower than that of parallel lines. The implementation procedures of the experimental design are also presented. The analysis of a $2^{k}$ factorial design with center points pertaining to the fine line printing experiment is discussed in detail.
\end{abstract}

Key Words: Screen Printing, Design of Experiments, Fine Line, Thick Film

\section{Introduction}

Surface Mount Technology (SMT) is the trend in electronic packaging and interconnection because it allows manufacturing lighter weight, smaller size, and higher performance products. SMT can be defined as the placement and attachment of surface mount components directly onto a pad on the substrate via a solder joint. In contrast, conventional technology is that the component's lead is connected to the substrate via a through-hole insertion and a solder joint. SMT first occurred in military and aerospace electronic products during the mid-1960s in order to achieve the highest electronic densities and performance. Today it is used in almost all types of electronic products from 
satellites to automobiles, computers to home appliances.

With a growing need for denser packaging and a drive for higher pin count, SMT has evolved from standard SMT to fine pitch SMT and ultra fine pitch SMT. There are two definitions of fine pitch. One is defined by the Institute for Interconnecting and Packaging Electronic Circuits (IPC) as leads from $100 \mu \mathrm{m}$ to $500 \mu \mathrm{m}$ (4 - $20 \mathrm{mils}$ ) (SMC-TR-001). The other is proposed by a printed circuit board consortium calling itself the "October Group" as a pitch of 500 - $1000 \mu \mathrm{m}(20-40$ mils), and ultra fine pitch for pitches of less than $500 \mu \mathrm{m}$ (20 mils) [1]. The latter definition of fine pitch and ultra fine pitch has been popularly used.

Screen printing technology began to be widely used to form conductors, resistors, and dielectrics during the mid-1960s. Nowadays screen printing has become the dominant method of thick film deposition. The advantages of screen printing are low cost, quick turn around, and good gasketing (no smear). However, finer powder (in the range of a few microns to submicrons) or low viscosity paste is required during screen printing. In addition, thick prints are difficult. These limitations make it difficult to print solder paste using screens with smaller pitch and higher lead count requirements. The main reasons are that solder pastes contain larger particles (in the range of approximately $75 \mu \mathrm{m}$ to a few microns) and are generally higher in viscosity than thick film inks.

\section{Review of Screen Printing Process}

A schematic of the screen printing process is shown in Figure 1. The screen is supported by the emulsion in the openings. The squeegee pushes down on the screen, causing the screen to come into contact with the substrate. When the squeegee is moved along the screen surface, it pushes the paste through the openings, which covers the desired areas of the substrate. Screening relies on a snap-off distance and the tension of the screen to cause the screen to peel out of the ink after the squeegee has gone by.

There are many variables that affect the printing process. The components of the screen printing process include the printer, the substrate, the screen, the squeegee, the thick film ink, and the process parameters. The detailed variables that influence the printing process are summarized in Figure 2. Screen printing quality indexes include mean print thickness, thickness uniformity, fine line resolution, and the number of voids.

The screen mesh count is a critical factor for controlling print thickness. Mesh count is the number of wires or openings (the linear distance between one wire to the next adjacent wire) per linear inch. Open area percentage is another important variable of screens that affects print quality.

Open area $\%=(1-\text { mesh count } \mathrm{x} \text { wire diameter })^{2} \times 100 \%$

In this equation, the units of mesh count and wire diameter are in inches. For example, a 325 mesh screen with $0.028 \mathrm{~mm}(0.0011 \mathrm{inch})$ wire diameter has an open area of $41 \%$. The greater the open area, the better the resolution capability of the screen. Mesh weave type, which includes plain weave, twilled weave, square weave, warp and weft wires, also influences print thickness. The screen mesh tension and the wire bias are two other important factors. Mesh tension is the tightness of the stretched mesh, measured in Newtons per centimeter. Proper mesh tension helps the ink release. If the tension is too high, it will be difficult to maintain proper snap-off distance. Furthermore, permanent damage can result if the yield point of the screen is exceeded. If the tension is too low, poor screen peel will result. Wire bias or mesh angle refers to the alignment angle between the mesh and the image. Biased screens with 30 degrees are recommended for fine line printing since they 
print more consistently. Mesh materials commonly used are stainless steel (type 304), monofilament nylon (polyamide), monofilament dacron (polyester), and metalized polyester.

Many experiments in industry have been done and many models of the printing process have been developed since the mid-1960s. Miller [2] studied the relationships between the amount of paste deposited and the screening process such as the mesh size, paste rheology, line width, etc. Austin [3] described the effects on printing thickness of squeegee attack angle, squeegee blade characteristic, and substrate variations. Bacher [4] investigated the effect of screens on high resolution prints. Riemer [5,6] presented a theory of the paste deposition process by screen printing. In his theory, the ink roll in front of the squeegee is treated as a pump generating high hydrostatic pressure close to the squeegee edge to inject ink into the screen meshes. Owczarek and Howland [7, 8 ] described a physical model of the screen printing process. They found that the angles of squeegees during printing decrease from the unformed angle of 45 degrees by about 20 degrees for hard squeegees (90 shore A) and by 30 - 40 degrees for soft squeegees (60 shore A). Parikh, Quilty, and Gardiner [9] discussed some key process variables that affect the repeatability of the screen printing process for thick-film circuits.

Fine line printing with various types of thick film inks has become a leading technology due to demand for smaller, lighter, and higher density products. In a recent analysis, boards with $125 \mu \mathrm{m}$ (5 mils) lines/spaces are the most cost-effective for Thin Quad Flat Pack (TQFP) and Plastic Ball Grid Array (PBGA), while boards with $100 \mu \mathrm{m}$ (4 mils) lines/spaces are the most cost-effective for $1.0 \mathrm{~mm}$ and $0.8 \mathrm{~mm}$ pitch Chip Scale Package (CSP) [10]. However, fine line printing, for example $100 \mu \mathrm{m}$ (4 mils) lines/spaces, is still considered by industry to be difficult for mass production. More research and experiments need to be done to improve screen printed fine line resolution.

The quality of fine line printing is affected by a considerable number of variables, such as wire bias of the screen, the quality of the screen emulsion, viscosity and rheology of inks, and printing process parameters. This paper focuses on investigating the effect of manufacturing process parameters on fine line printing through the use of statistical design of experiments (DOE).

\section{Design of Experiments}

The goal of this experiment was to investigate the effect of the manufacturing process parameters on fine line printing. After the printing process was carefully reviewed, four factors were considered to be important variables on fine line printing quality and were chosen in this study. They were print speed, squeegee hardness, squeegee pressure, and snap-off distance. The response variables were defined as space width of $0.25 \mathrm{~mm}(10 \mathrm{mil}), 0.2 \mathrm{~mm}(8 \mathrm{mil})$, and $0.125 \mathrm{~mm}$ (5mil) lines in both parallel and perpendicular directions relative to the squeegee travel direction. Figure 3 shows the inputs and outputs of this experiment.

The test pattern is shown in Figure 4. The pattern contained a group of different line widths: nominal $0.125 \mathrm{~mm}(5 \mathrm{mil}), 0.2 \mathrm{~mm}(8 \mathrm{mil})$, and $0.25 \mathrm{~mm}(10 \mathrm{mil})$ line widths in both parallel and perpendicular directions. Each group had 5 lines/spaces.

In order to limit the number of experimental runs, a $2^{4}$ factorial design with center points was selected. The center point refers to setting all factors at the middle level. Replication is essential to estimate the interaction between the factors. So a total of $2^{*}\left(2^{4}+1\right)=34$ runs were done. The $2^{4}$ factorial design with center points provides an estimate of error, check for interactions, and check for quadratic effects. Table 1 summarizes the factors and levels for the experiment. Table 2 illustrates 
the DOE matrix. The next step was to randomize the order of the treatments. It should be noted that the randomization of the order of treatments is the cornerstone underlying the use of statistical methods in experimental design. The assumption that the observations are independently distributed random variables is made valid by properly randomizing the experiments.

The substrates used in this experiment were 50x50 mm ( $2 \times 2$ inches) $96 \%$ alumina. The paste was $\mathrm{Ag} / \mathrm{Pd}$ conductor paste. The polyurethane squeegee was set at 45 degrees. The screen was $325 \mathrm{mesh}, 28 \mu \mathrm{m}(1.1 \mathrm{mil})$ wire diameter, $7.6 \mu \mathrm{m}(0.3 \mathrm{mil})$ emulsion. After printing, the substrates were dried and fired.

A microscope was used to measure the width of each space between lines at 10 points. 2 spaces per group per print were measured yielding $2 \times 3 \times 10=60$ width measurements per print and a total of $34 \times 60=2,040$ points in this experiment.

Height information of the printed deposits is also very important. For example, when a resistor is printed, the value of resistance varies inversely with the film thickness. In this research an attempt was also made to measure the height of each line and investigate the effect of the 4 input variables on the height of the printed deposit. A laser based measurement machine called a MicroScan with a sensor resolution of $0.75 \mu \mathrm{m}$ was used. However, because the ceramic substrate is a translucent material, it was difficult to measure with an optical probe. The reason is that light penetrates the ceramic surface and is reflected from areas below the ceramic surface as well as from the ceramic surface itself. Figure 5 shows the measurement results of one printed sample. Here two questions were raised. One is how to determine the reference plane of the substrate since large deviations of the measured results of the ceramic substrate occurred due to the reflections. In addition, the ceramic substrate surface is not perfectly flat so reference data must be obtained close to the measured deposits. The other question is which height information should be used to compare the effects of the input variables, top height or average height. If the average height is selected, how should the average height be calculated?

Figures 6 and 7 show some photographs of the printed deposits. It shows that the printed results become poor when the line widths become narrow. More voids and more connections were observed between two adjacent lines on $0.125 \mathrm{~mm}(5 \mathrm{mil})$ and $0.2 \mathrm{~mm}(8 \mathrm{mil})$ lines than $0.25 \mathrm{~mm}$ (10 mil) lines.

\section{Analysis of the data}

The data results (mean line width and standard deviation of line width) were analyzed using Analysis of Variance (ANOVA). It should be noted that the usual ANOVA in a $2^{\mathrm{k}}$ design does not need center points. The center points are only used for a regression model.

\subsection{ANOVA}

Before analysis of variance, the adequacy of the model should be investigated. The adequacy of the model consists of checking the normality assumption, uniform variance, and independence of errors. The check of the normality assumption uses the normal probability plot. Figure 8 illustrates the normal probability plot for the mean width of $0.2 \mathrm{~mm}$ (8mil) parallel lines. Figure 8 shows nothing unusual. The plot of residual versus predicted in Figure 9 and the plot of residual versus experiment sequence in Figure 10 indicate that the uniform variance and independence assumptions are valid.

The analysis of variance for the mean width of $0.2 \mathrm{~mm}(8 \mathrm{mil})$ parallel lines is shown in Table 
3. The P-values test the statistical significance of each of the factors. Since the P-values of squeegee hardness and squeegee speed are less than 0.05 , these factors have a statistically significant effect on mean width of $0.2 \mathrm{~mm}$ (8mil) parallel lines at the $95.0 \%$ confidence level.

The ANOVA for the deviation of $0.25 \mathrm{~mm}$ (10 mil) parallel line width is shown in Table 4. For $0.25 \mathrm{~mm}$ (10 mil) parallel line widths, print speed has a statistically significant effect on the line width deviation at the $95 \%$ confidence level. The higher the print speed, the larger the space width deviation. For $0.25 \mathrm{~mm}$ (10 mil) perpendicular space widths, there is no statistically significant effect of the 4 input variables on the space width deviation. It should be pointed out that the only space width deviation that could be analyzed was for $0.25 \mathrm{~mm}$ (10 mil). The deviations of $0.2 \mathrm{~mm}$ ( $8 \mathrm{mil})$ space widths and $0.125 \mathrm{~mm}$ ( $5 \mathrm{mil}$ ) space widths could not be analyzed because adjacent lines were often connected for certain input combinations. This provided a false value for space width which skewed the results. Further experiments with an altered test pattern could provide more space between lines to determine the effects or the experimental conditions could be changed.

Table 4 summaries the significant main effects for all response variables. "Mean 10 Par" means the mean width of $0.25 \mathrm{~mm}$ (10mil) parallel lines, and "Dev. 10 Per" means the standard deviation of $0.25 \mathrm{~mm}$ (10mil) perpendicular line widths. Here "Mean 5 Per" is not shown in Table 5 because there were many connections between adjacent lines so that the space widths were all zero.

\subsection{Regression model}

From Table 5, we know that squeegee hardness and squeegee speed have statistically significant effects on fine line printing, while snap-off distance and squeegee pressure do not have significant effects at the designed level described in Table 1.

A potential concern in the use of a $2^{\mathrm{k}}$ fractional design is the assumption of linearity in the factor effects. Next a check was performed to determine whether a quadratic effect existed between squeegee hardness and squeegee speed. Note that all experimental data including center points are used for this analysis. The regression model is:

$y=\beta_{0}+\beta_{1} \mathrm{SH}+\beta_{2} \mathrm{SS}+\beta_{3} \mathrm{SHSS}+\beta_{4}\left(\mathrm{SS}^{2}+\mathrm{SH}^{2}\right)+\varepsilon$

where

$\mathrm{y}$ is the measured experimental value of a response variable;

$\beta_{0,} \beta_{1}, \beta_{2}, \beta_{3}, \beta_{4}$ are coefficients;

$\mathrm{SH}$ is level of squeegee hardness $(\mathrm{High}=1$, middle $=0$, low $=-1$ )

$\mathrm{SS}$ is level of squeegee speed (High $=1$, middle $=0$, low $=-1$ ).

Note that $\mathrm{SS}^{2}$ and $\mathrm{SH}^{2}$ are confounded here because the $2^{2}$ design plus center points only has five independent runs so that we can only estimate 5 coefficients. The regression analysis indicates that there are no quadratic effects of squeegee hardness and squeegee speed. The scatter plot of the mean width of $0.2 \mathrm{~mm}$ ( $8 \mathrm{mil}$ ) parallel lines versus the squeegee hardness and the squeegee speed is shown in Figure 11. It indicates that the harder the squeegee and the lower the squeegee speed, the better the printed results.

\section{Conclusions}

A hard squeegee should be utilized in fine line printing. The squeegee hardness is the most important variable that influences the printing results obtained. 
The snap-off distance and squeegee pressure at the experimental levels in these tests do not have significant effects on fine line printing, but they may relate to the selection of the screen tension.

The squeegee speed has a significant effect on lines that are parallel to the squeegee traveling direction. At the experimental levels, the lower the print speed, the better the printed results.

The yield of printed substrates with $0.125 \mathrm{~mm}(5 \mathrm{mil})$ lines is poorer than that of $0.2 \mathrm{~mm}(8$ mil) and $0.25 \mathrm{~mm}$ (10 mil) lines. Specifically, the printed deposits of $0.125 \mathrm{~mm}$ (5 mil) width lines have more voids or more connections between two adjacent lines. This means the process operating window becomes narrower in fine line printing and more strict process control is needed.

These experiments only focus on the printing process, more follow up experiments with additional emphasis on screen mesh, emulsion, paste, substrate, and cleaning techniques need to be performed.

\section{Acknowledgments}

The authors would like to thank Randy Hume and Donald Havas of Visteon, Thomas Green of the National Training Center for Microelectronics at Northampton Community College for fruitful discussions on the screen printing process. We appreciate valuable advice on the design and analysis of this experiment from Dr. Robert Storer. Thanks are due to Kannachai Kanlayasiri for his help in collecting the data and Don Pierce of Pleiger Plastics Co., PA for providing the squeegees. Equipment for this experiment was provided by NSF grant No. 9552137.

\section{Biography}

Jianbiao Pan is currently a Ph.D. candidate in the Department of Industrial \& Manufacturing Systems Engineering at Lehigh University. His current research interest is in electronics manufacturing process modeling and optimization. He has expertise in surface mount technology, thick film hybrids and design of experiments, and published several technical papers. He is a member of IMAPS, IEEE, and SME.

Dr. Gregory L. Tonkay is Associate Professor in the Department of Industrial and Manufacturing Systems Engineering at Lehigh University. He is the Director of the Electronics Manufacturing Laboratory and Associate Director of the George E. Kane Manufacturing Technology Laboratory. He has authored or coauthored over 25 technical papers. His areas of interest are manufacturing, automation, electronics manufacturing, and engineering education.

Alejandro Quintero is a senior majoring in Industrial Engineering with a minor in Portuguese at Lehigh University. He was a recipient of the 1997 General Electric Company Undergraduate Research and Fellowship Awards.

\section{References}

[1] Charles I. Hutchins, "Understanding and Using Surface Mount and Fine Pitch Technology Including Ball Grid Array", SMTnet, 1996.

[2] L. F. Miller, "Paste Transfer in the Screening Process", Solid State Technology, June 1969, pp. 46- 
52.

[3] Benson M. Austin, “Thick-Film Screen Printing”, Solid State Technology, June 1969, pp. 53 - 58.

[4] Rudolph J. Bacher, "High Resolution Thick Film Printing", Proceedings of the International Symposium on Microelectronics, 1986, pp. 576 - 581.

[5] Dietrich E. Riemer, "Analytical Engineering Model of the Screen Printing Process: Part I", Solid State Technology, August 1988, pp. 107 - 111.

[6] Dietrich E. Riemer, "Analytical Engineering Model of the Screen Printing Process: Part II", Solid State Technology, September 1988, pp. 85 - 90.

[7] Jerzy A. Owczarek and Frank L. Howland, "A Study of the Off-Contact Screen Printing Process Part I: Model of the Printing Process and Some Results Derived From Experiments", IEEE Transactions on Components, Hybrids, and Manufacturing Technology, Vol. 13, No. 2, pp. 358 367, June 1990.

[8] Jerzy A. Owczarek and Frank L. Howland, "A Study of the Off-Contact Screen Printing Process Part II: Analysis of the Model of the Printing Process", IEEE Transactions on Components, Hybrids, and Manufacturing Technology, Vol. 13, No. 2, pp. 368 - 375, June 1990.

[9] Mayank R. Parikh, William F Quilty, Jr., and Keith M. Gardiner, "SPC ans setup analysis for screen printed thick films", IEEE Transactions on Components, Hybrids, and Manufacturing Technology, Vol. 14, No. 3, pp. 493 - 498, Sep. 1991.

[10] Jan Vardaman, "What Does a CSP Cost", Guide to Emerging Technologies, special supplement to Advanced Packaging, July/August 1997, pp. 3 - 4.

[11] Douglas C. Montgomery, "Design and Analysis of Experiments", John Wiley \& Sons, fourth edition, New York, 1997. 
Table 1. Factors and Levels

\begin{tabular}{|l|l|l|l|}
\hline Parameter & High & Middle & Low \\
\hline Squeegee hardness (shore type A) & 90 & 80 & 70 \\
\hline Snap-off distance (mils) & 50 & 40 & 30 \\
\hline Squeegee Pressure & High & Middle & Low \\
\hline Squeegee speed (inch/sec.) & 7 & 6 & 5 \\
\hline
\end{tabular}


Table 2. $2^{4}$ factorial with a center point design matrix

\begin{tabular}{|l|l|l|l|l|}
\hline Run No. & Squeegee pressure & Squeegee hardness & Snap-off distance & Squeegee speed \\
\hline 1 & L & L & L & L \\
\hline 2 & H & L & L & L \\
\hline 3 & L & H & L & L \\
\hline 4 & H & H & L & L \\
\hline 5 & L & L & H & L \\
\hline 6 & H & L & H & L \\
\hline 7 & L & H & H & L \\
\hline 8 & H & H & H & L \\
\hline 9 & L & L & L & H \\
\hline 10 & H & L & L & H \\
\hline 11 & L & H & L & H \\
\hline 12 & H & L & L & H \\
\hline 13 & L & L & H & H \\
\hline 14 & H & H & H & H \\
\hline 15 & L & H & H & H \\
\hline 16 & H & M & M & M \\
\hline 17 & M & & & \\
\hline
\end{tabular}


Table 3. ANOVA for mean width of $0.2 \mathrm{~mm}$ (8 mil) parallel lines.

\begin{tabular}{|l|l|l|l|l|l|}
\hline Source & Sum of Squares & Df & $\begin{array}{l}\text { Mean } \\
\text { square }\end{array}$ & F-ratio* & P value \\
\hline Main effects & & & & & \\
\hline A:Snap-off Distance & 0.01162 & 1 & 0.01162 & 0.00 & 0.9635 \\
\hline B:Squeegee Hardness & 160.967 & 1 & 160.967 & 29.61 & 0.0000 \\
\hline C:Squeegee Pressure & 10.4082 & 1 & 10.4082 & 1.91 & 0.1810 \\
\hline D:Squeegee Speed & 39.4494 & 1 & 39.4494 & 7.26 & 0.0136 \\
\hline Interactions & & & & & \\
\hline AB & 5.85675 & 1 & 5.85675 & 1.08 & 0.3111 \\
\hline AC & 11.1038 & 1 & 11.1038 & 2.04 & 0.1677 \\
\hline AD & 2.4145 & 1 & 2.4145 & 0.44 & 0.5124 \\
\hline BC & 4.41788 & 1 & 4.41788 & 0.81 & 0.3776 \\
\hline BD & 6.74363 & 1 & 6.74363 & 1.24 & 0.2780 \\
\hline CD & 0.37195 & 1 & 0.37195 & 0.07 & 0.7962 \\
\hline RESIDUAL & 114.169 & 21 & 5.43664 & & \\
\hline Total (corrected) & 355.914 & 31 & & & \\
\hline
\end{tabular}

* All F-ratios are based on the residual mean square error. 
Table 4. ANOVA for standard deviation of $0.25 \mathrm{~mm}(10 \mathrm{mil})$ parallel line widths.

\begin{tabular}{|l|l|l|l|l|l|}
\hline Source & Sum of Squares & Df & Mean square & F-ratio* & P value \\
\hline Main effects & & & & & \\
\hline A:Snap-off Distance & 0.255183 & 1 & 0.255183 & 0.28 & 0.6045 \\
\hline B:Squeegee Hardness & 1.26343 & 1 & 1.26343 & 1.37 & 0.2550 \\
\hline C:Squeegee Pressure & 0.756583 & 1 & 0.756583 & 0.82 & 0.3754 \\
\hline D:Squeegee Speed & 4.33313 & 1 & 4.33313 & 4.70 & 0.0419 \\
\hline Interactions & & & & & \\
\hline AB & 0.976477 & 1 & 0.976477 & 1.06 & 0.3153 \\
\hline AC & 1.4443 & 1 & 1.4443 & 1.57 & 0.2246 \\
\hline AD & 3.03265 & 1 & 3.03265 & 3.29 & 0.0842 \\
\hline BC & 2.26698 & 1 & 2.26698 & 2.46 & 0.1319 \\
\hline BD & 0.334124 & 1 & 0.334124 & 0.36 & 0.5538 \\
\hline CD & 1.06509 & 1 & 1.06509 & 1.15 & 0.2948 \\
\hline RESIDUAL & 19.3752 & 21 & 0.922628 & & \\
\hline Total (corrected) & 35.1031 & 31 & & & \\
\hline
\end{tabular}

* All F-ratios are based on the residual mean square error. 
Table 5. Summary of significant effects for all response variables.

\begin{tabular}{|l|l|l|l|l|}
\hline & $\begin{array}{l}\text { Snap-off } \\
\text { Distance }\end{array}$ & $\begin{array}{l}\text { Squeegee } \\
\text { Hardness }\end{array}$ & $\begin{array}{l}\text { Squeegee } \\
\text { Pressure }\end{array}$ & Squeegee Speed \\
\hline Mean 10 Par & No & Yes & No & Yes \\
\hline Mean 10 Per & No & Yes & No & No \\
\hline Mean 8 Par & No & Yes & No & Yes \\
\hline Mean 8 Per & No & Yes & No & No \\
\hline Mean 5 Par & No & Yes & No & Yes \\
\hline Dev. 10 Par & No & No & No & Yes \\
\hline Dev. 10 Per & No & No & No & No \\
\hline
\end{tabular}




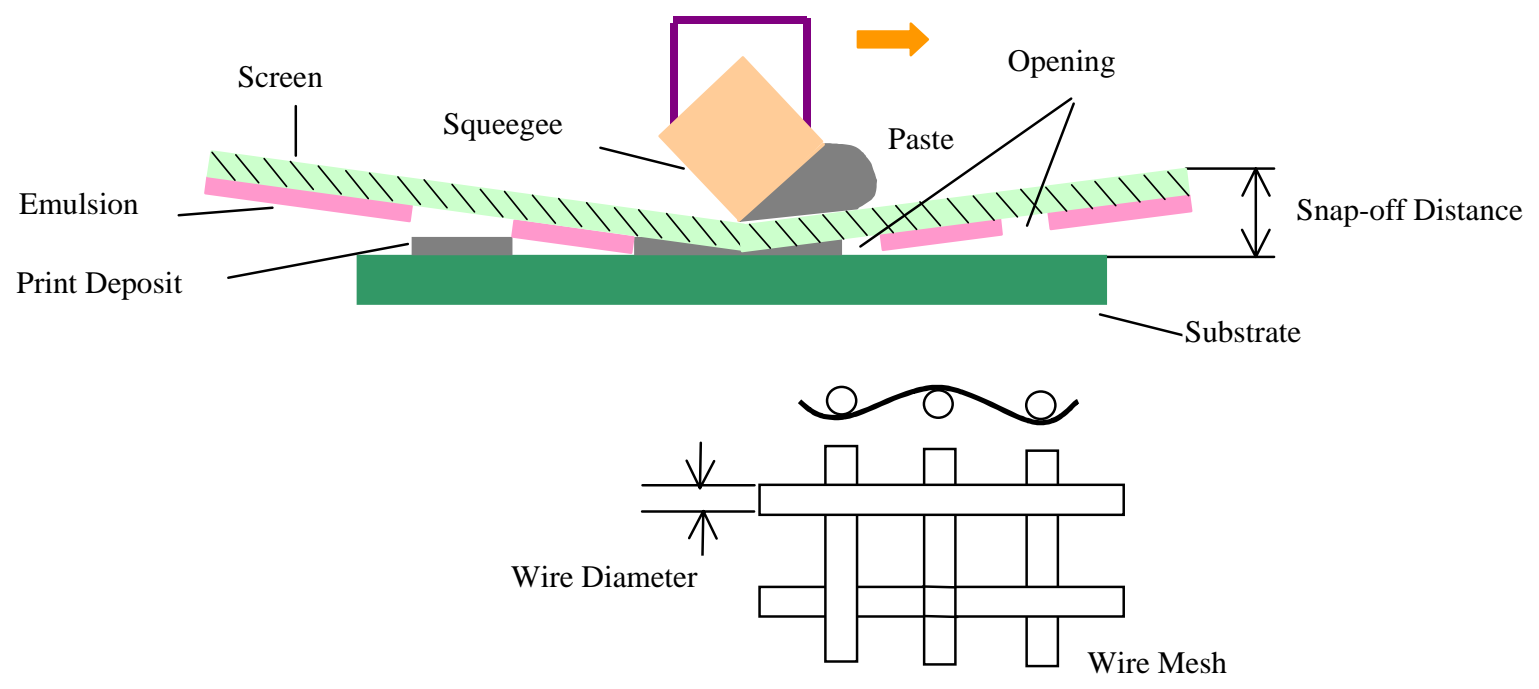

Figure 1. Schematic diagram of the screen printing process 


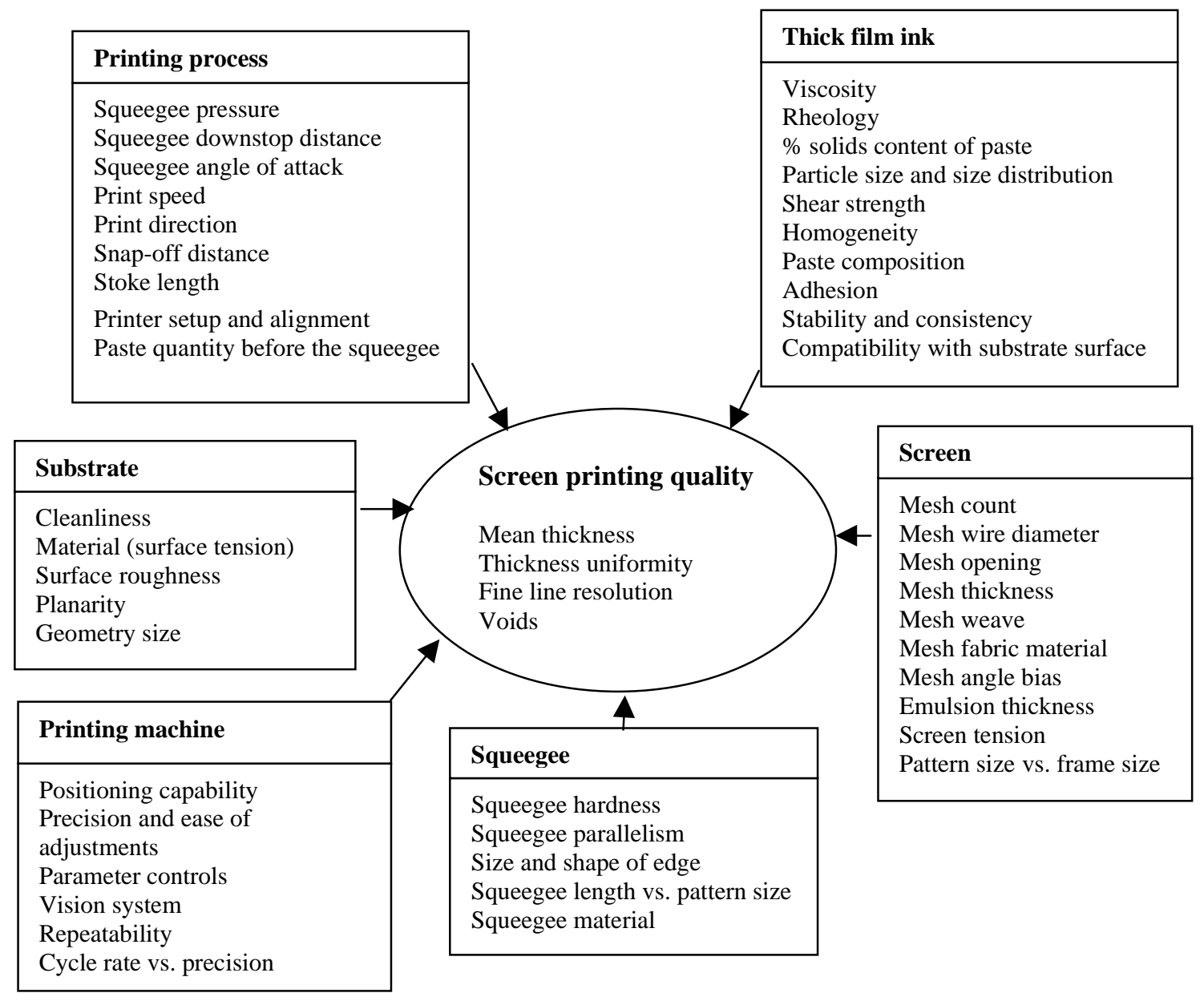

Figure 2. Factors that influence the screen printing quality 


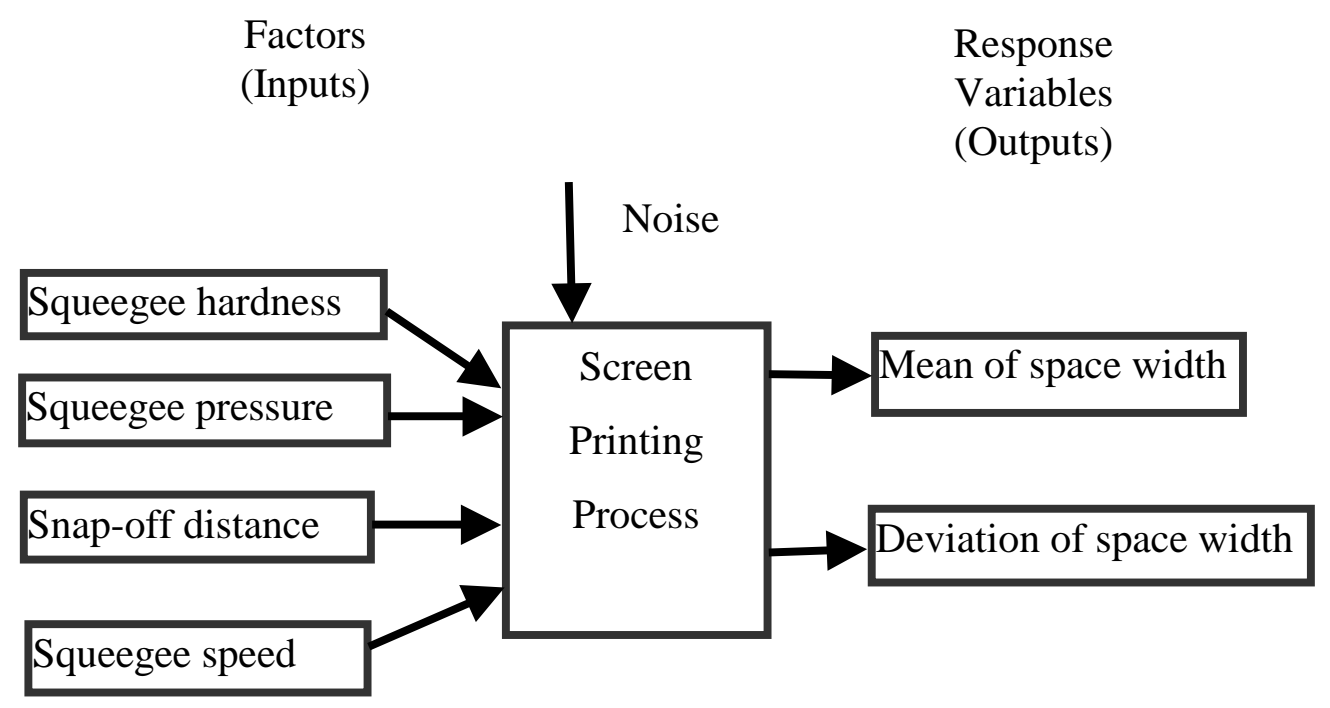

Figure 3. Inputs and outputs 


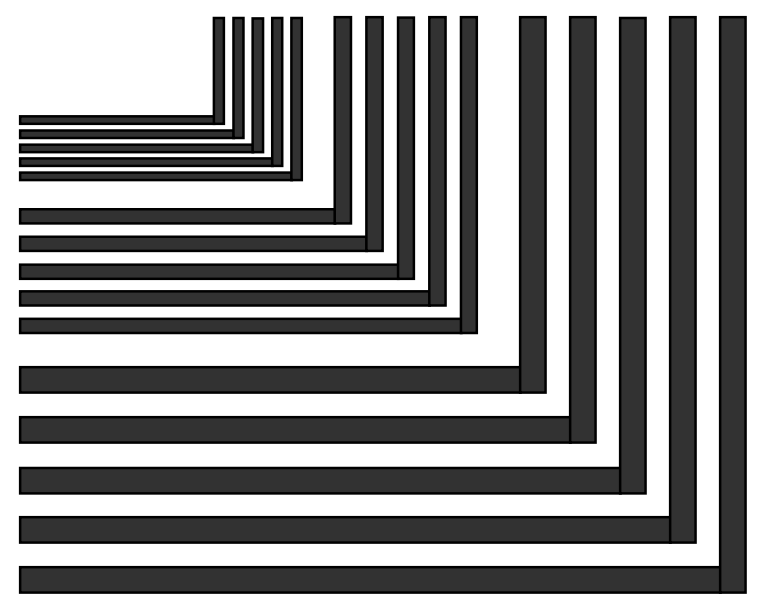

Figure 4. The test pattern 


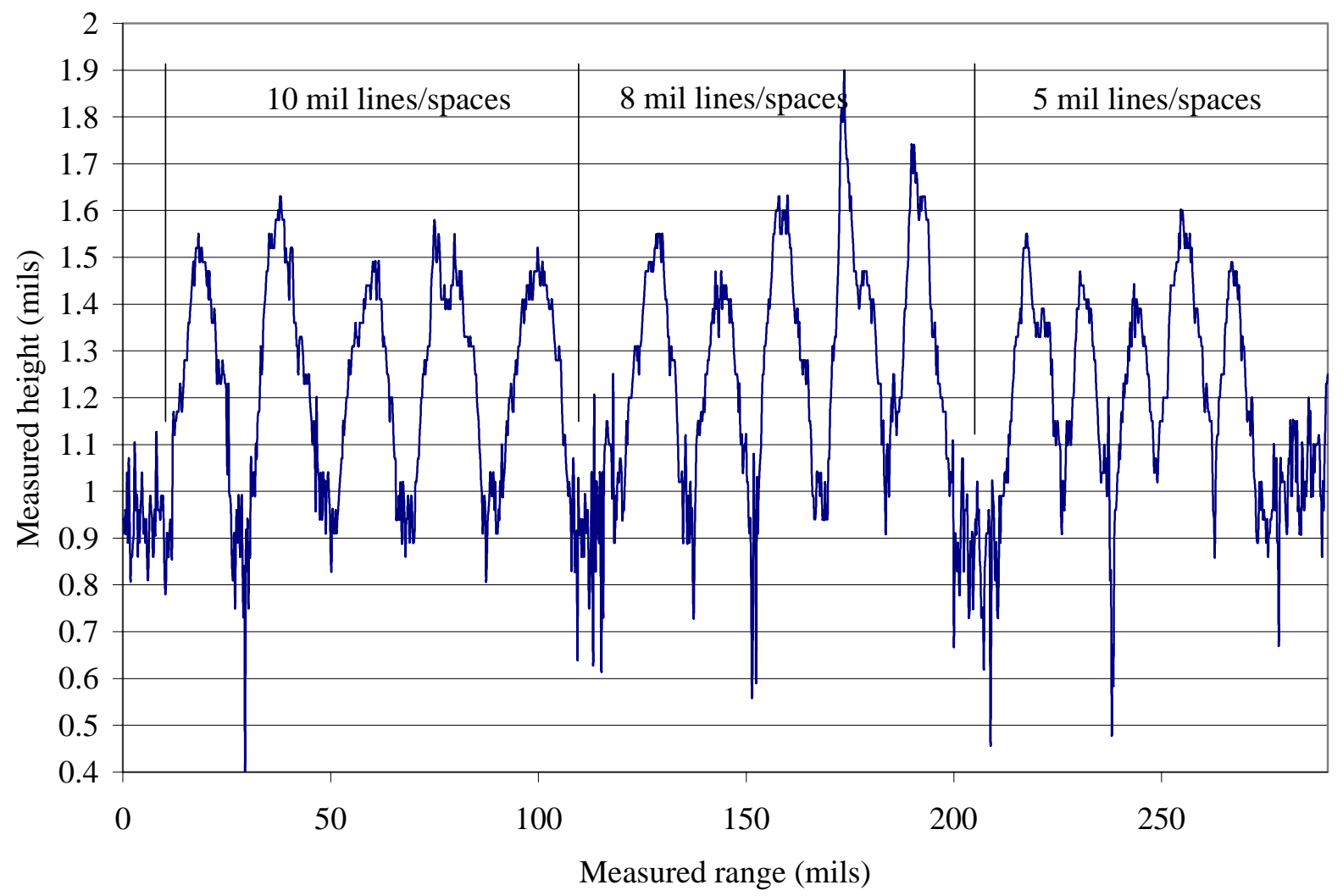

Figure 5. Example of a height profile using MicroScan 


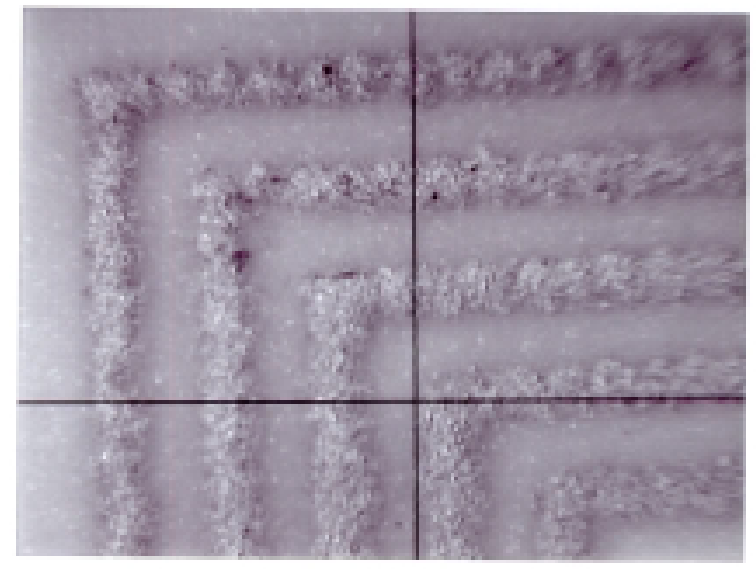

(a)

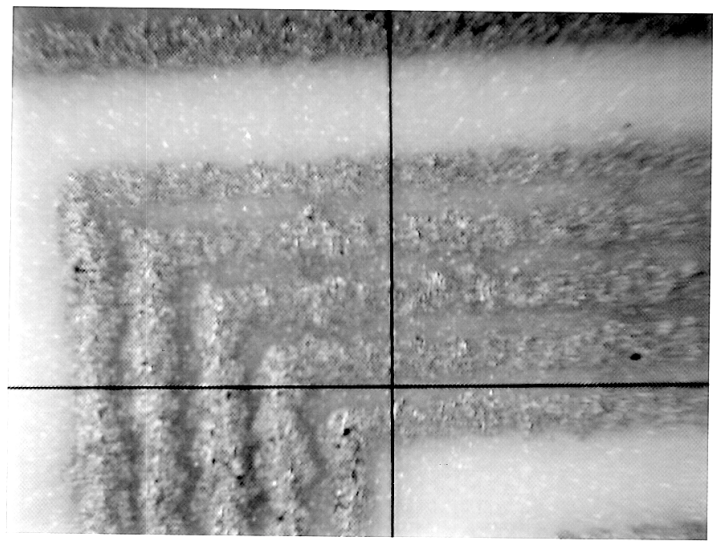

(c)

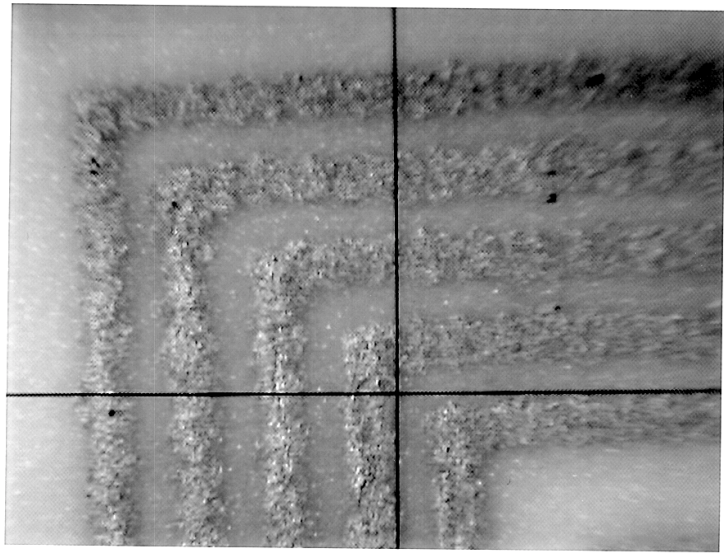

(b)

Figure 6. Photographs of deposits printed with squeegee hardness: 90, squeegee pressure: high, snapoff distance: $30 \mathrm{mils}$, and squeegee speed: $5 \mathrm{inch} / \mathrm{sec}$. (a) $0.25 \mathrm{~mm}$ (10 mil) line, (b) $0.2 \mathrm{~mm}$ (8 mil) line, (c) $0.125 \mathrm{~mm}$ (5 mil) line.

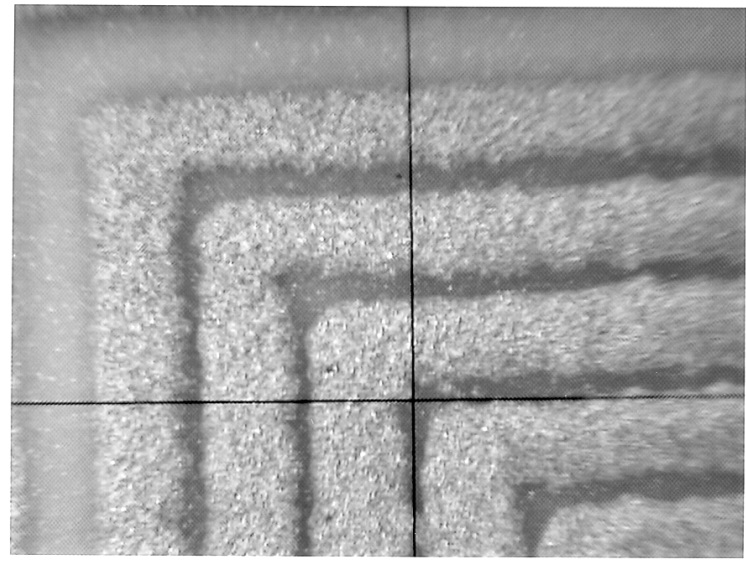

(a)

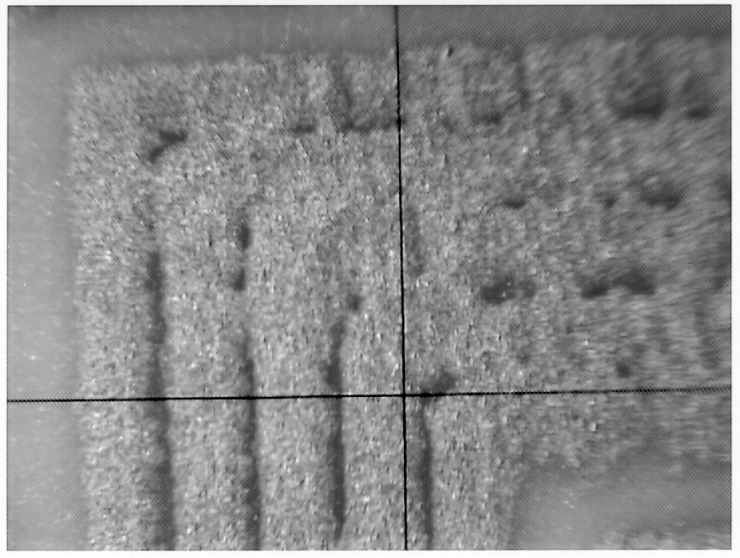

(b)

Figure 7. Photographs of deposits printed with squeegee hardness: 70, squeegee pressure: high, snapoff distance: $30 \mathrm{mils}$, and squeegee speed: $8 \mathrm{inch} / \mathrm{sec} .:$ (a) $0.25 \mathrm{~mm}$ (10 mil) line, (b) $0.2 \mathrm{~mm}$ (8 mil) line. 


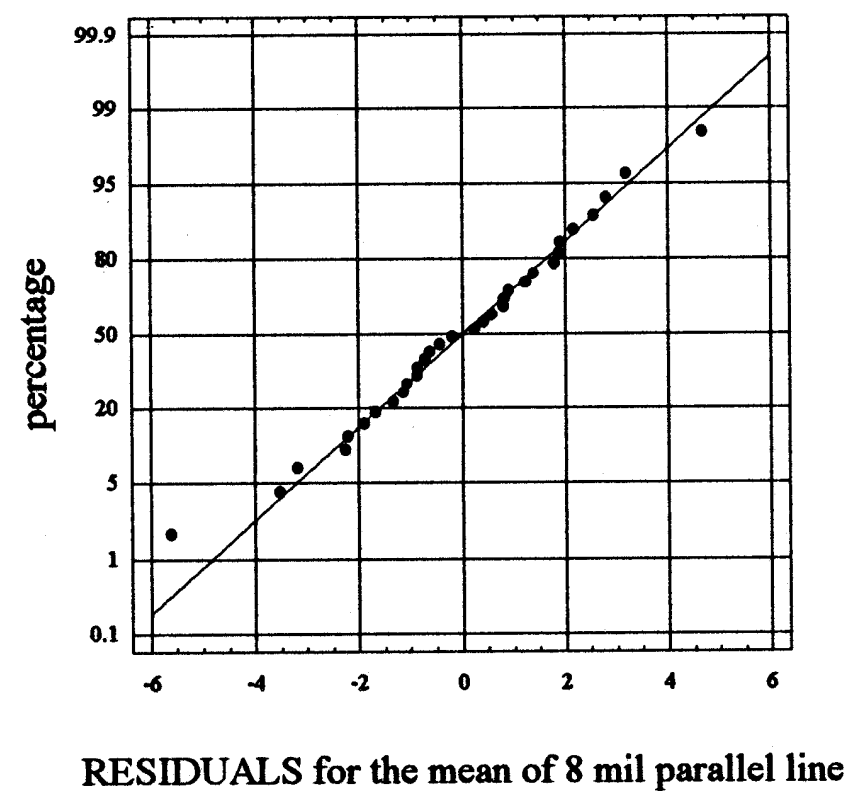

Figure 8 . Normal probability plot for residuals of mean of $0.2 \mathrm{~mm}$ ( 8 mil) lines 


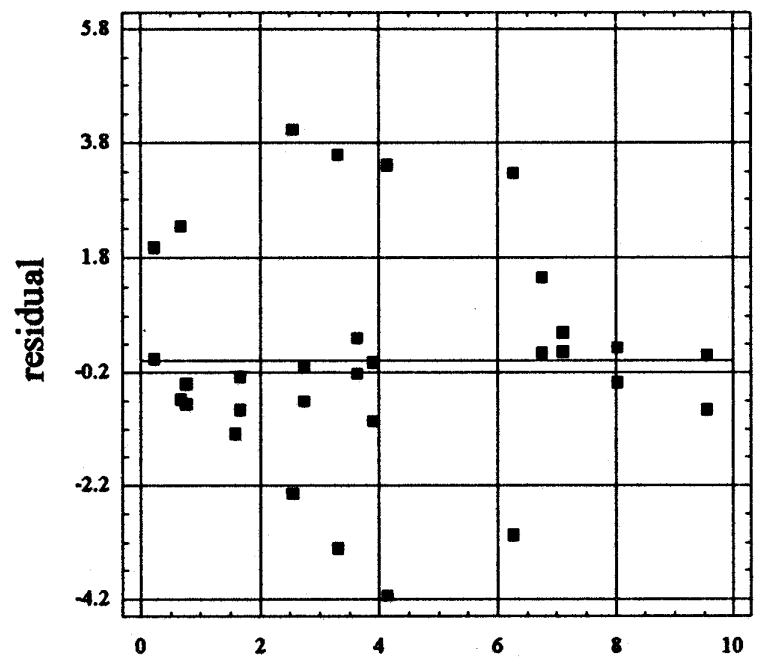

Predicted values of the mean of $8 \mathrm{mil}$ parallel line

Figure 9. Plot of residuals versus predicted values 


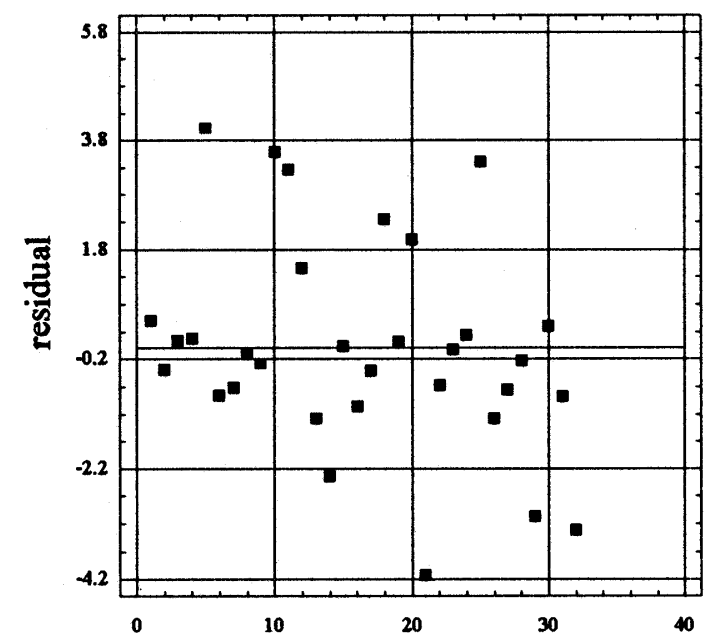

Experimental sequence

Figure 10. Plot of residuals versus experimental sequence

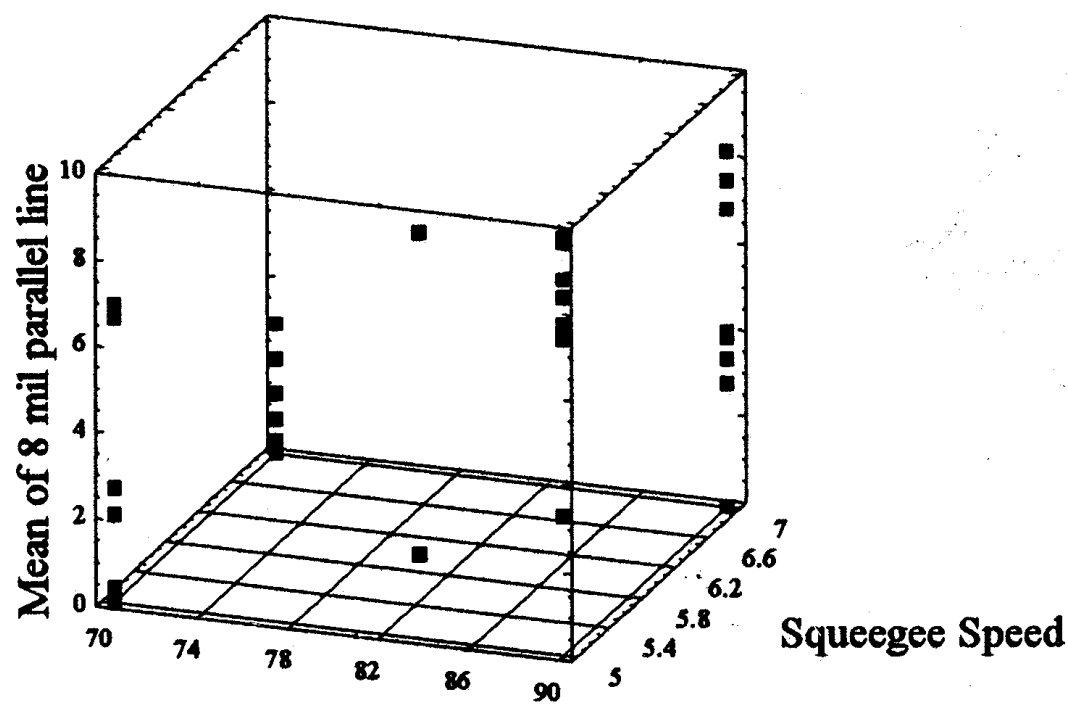

Squeegee Hardness

Figure 11. Plot of mean width of $0.2 \mathrm{~mm}$ ( 8 mil) parallel lines versus squeegee hardness and squeegee speed 